\title{
Evidence of primary cilia in the developing rat heart
}

\author{
Sarbjot Kaur ${ }^{1}$, Sue R. McGlashan² and Marie-Louise Ward ${ }^{1 *}$ (⿺辶)
}

\begin{abstract}
Background: A transient increase in cytosolic $\mathrm{Ca}^{2+}$ (the " $\mathrm{Ca}^{2+}$ transient") determines the degree and duration of myocyte force development in the heart. However, we have previously observed that, under the same experimental conditions, the $\mathrm{Ca}^{2+}$ transients from isolated cardiac myocytes are reduced in amplitude in comparison to those from multicellular cardiac preparations. We therefore questioned whether the enzymatic cell isolation procedure might remove structures that modulate intracellular $\mathrm{Ca}^{2+}$ in some way. Primary cilia are found in a diverse range of cell types, and have an abundance of $\mathrm{Ca}^{2+}$-permeable membrane channels that result in $\mathrm{Ca}^{2+}$ influx when activated. Although primary cilia are reportedly ubiquitous, their presence and function in the heart remain controversial. If present, we hypothesized they might provide an additional $\mathrm{Ca}^{2+}$ entry pathway in multicellular cardiac tissue that was lost during cell isolation. The aim of our study was to look for evidence of primary cilia in isolated myocytes and ventricular tissue from rat hearts.

Methods: Immunohistochemical techniques were used to identify primary cilia-specific proteins in isolated myocytes from adult rat hearts, and in tissue sections from embryonic, neonatal, young, and adult rat hearts. Either mouse anti-acetylated a-tubulin or rabbit polyclonal ARL13B antibodies were used, counterstained with Hoechst dye. Selected sections were also labelled with markers for other cell types found in the heart and for myocyte F-actin.

Results: No evidence of primary cilia was found in either tissue sections or isolated myocytes from adult rat ventricles. However, primary cilia were present in tissue sections from embryonic, neonatal (P2) and young (P21 and P28) rat hearts.

Conclusion: The lack of primary cilia in adult rat hearts rules out their contribution to myocyte $\mathrm{Ca}^{2+}$ homoeostasis by providing a $\mathrm{Ca}^{2+}$ entry pathway. However, evidence of primary cilia in tissue from embryonic and very young rat hearts suggests they have a role during development.
\end{abstract}

Keywords: Primary cilia, ARL13B, Rat cardiac tissue, Cardiac trabeculae, Isolated cardiomyocytes

\section{Background}

Intracellular $\mathrm{Ca}^{2+}$ has a crucial role in the heart's contraction, directly controlling the force developed by the myocytes with every heart "beat". Cyclical changes in intracellular $\mathrm{Ca}^{2+}$ are initiated by the cardiac action potential, known as the " $\mathrm{Ca}^{2+}$ transient", and form the basis of excitation-contraction coupling in the heart (for review see [1]). $\mathrm{Ca}^{2+}$ homoeostasis within myocytes

\footnotetext{
*Correspondence: m.ward@auckland.ac.nz

${ }^{1}$ Department of Physiology, School of Medical Sciences, Faculty of Medical and Health Sciences, The University of Auckland, Private Bag 92019, Auckland 1023, New Zealand

Full list of author information is available at the end of the article
}

is therefore of major importance to the function of the heart, since all myocytes contribute to every heartbeat. Small alterations in the amplitude and/or the time course of the $\mathrm{Ca}^{2+}$ transient are immediately reflected in the force developed during subsequent contraction. Previously, we have observed that isolated myocytes were depotentiated, with low-amplitude $\mathrm{Ca}^{2+}$ transients in comparison to those from multicellular ventricular trabeculae under the same experimental conditions [2]. A major difference between isolated myocytes and intact cardiac preparations, such as trabeculae, is the loss of the extracellular matrix during the cell isolation process. We therefore questioned whether transmembrane spanning structures that modulate intracellular $\mathrm{Ca}^{2+}$ in other cell

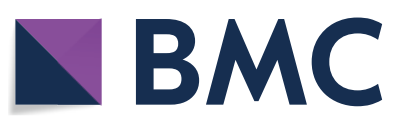

(c) The Author(s) 2018. This article is distributed under the terms of the Creative Commons Attribution 4.0 International License (http://creativecommons.org/licenses/by/4.0/), which permits unrestricted use, distribution, and reproduction in any medium, provided you give appropriate credit to the original author(s) and the source, provide a link to the Creative Commons license, and indicate if changes were made. The Creative Commons Public Domain Dedication waiver (http://creativecommons.org/ publicdomain/zero/1.0/) applies to the data made available in this article, unless otherwise stated. 
types, such as primary cilia [3], might also have a role in the heart. We hypothesized that the primary cilia may be lost during the enzymatic myocyte isolation process, leading to a net loss of intracellular $\left[\mathrm{Ca}^{2+}\right]$ and reduced $\mathrm{Ca}^{2+}$ transients.

The primary cilium is a solitary, non-motile organelle that is an extension of the basal body and is ubiquitously expressed in mammalian cell types [4, 5]. As sensory organelles, they transduce external forces, perhaps via intracellular $\mathrm{Ca}^{2+}$ signals [6] (but see [7]), coordinating multiple signalling pathways [8-13]. Defects lead to several human diseases collectively known as 'ciliopathies' $[14,15$, reviewed in 21,22$]$, with instances of impaired left ventricular function and diffuse interstitial fibrosis of the heart [16]. Primary cilia are reportedly important in the development of a number of organs $[17,18]$. However, primary cilia in adult cardiac myocytes, and their possible contribution to intracellular $\left[\mathrm{Ca}^{2+}\right]_{\mathrm{i}}$ modulation, have not been fully investigated.

The aim of this study was therefore to look for the evidence of primary cilia in situ in young and adult ventricular tissue, and in isolated myocytes, from rat hearts through immunohistochemistry and confocal microscopy.

\section{Methods}

Methods relating to the cardiac myocyte isolation procedure are provided in the Additional file 1, together with details of the solutions, reagents, and chemicals used.

\section{Results}

Immunolabelling in adult single cardiomyocytes and cardiac tissue

Figure 1a shows a representative confocal image taken at the surface of a mature isolated myocyte labelled for acetylated- $\alpha$-tubulin. A very bright region of labelling near the nucleus was observed in all cells (20-50 cells, from $n=2$ hearts). A fine network of positively stained microtubules was also seen within all of the myocytes, showing that the acetylated- $\alpha$-tubulin antibody labels cytoplasmic tubulin, and not just primary cilia. In rat ventricular tissue sections, intense staining of the extracellular spaces between myocytes, along with some intracellular labelling, was also observed (Fig. 1b; see Additional file 2: Figure S2 for details). These results showed that acetylated $\alpha$-tubulin was not a reliable primary antibody for identification of primary cilia in adult rat tissue. Therefore, ARL13B was used in further experiments [19-21]. Kidney sections from adult rats were also labelled with, and without, primary antibodies (anti-acetylated $\alpha$-tubulin/anti-ARL13B) to provide positive and negative controls (Additional file 3: Figure S1). Confocal images showed no evidence of primary cilia in rat tissue sections $(n=4$ hearts, with at least five sections from each heart), or in isolated myocytes $(n=4$ hearts, $20-50$ cells per heart) from adult ( 2 months of age) rat hearts, with representative images shown in Fig. 2.
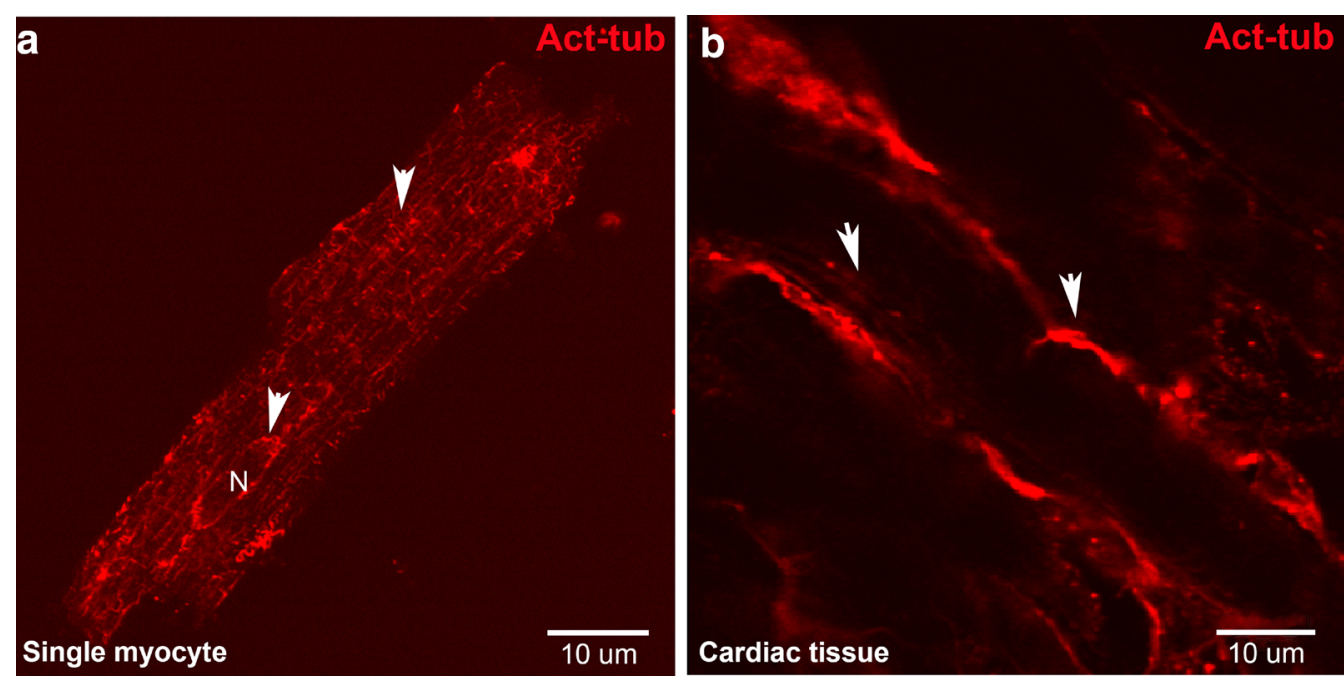

Fig. 1 Acetylated-a-tubulin in single myocyte and cardiac tissue. Confocal images of $\mathbf{a}$ a representative adult rat cardiomyocyte and $\mathbf{b}$ adult rat ventricular tissue, immunolabelled for acetylated a-tubulin. ' $N$ 'shows the nucleus. A fine network of cytoplasmic tubulin labelling is present in $\mathbf{a}$, with dense labelling close to the nuclear regions shown by arrows. Arrowheads indicate intense tubulin labelling in between myocytes in extracellular spaces in the representative cardiac tissue section shown in $\mathbf{b}$ 

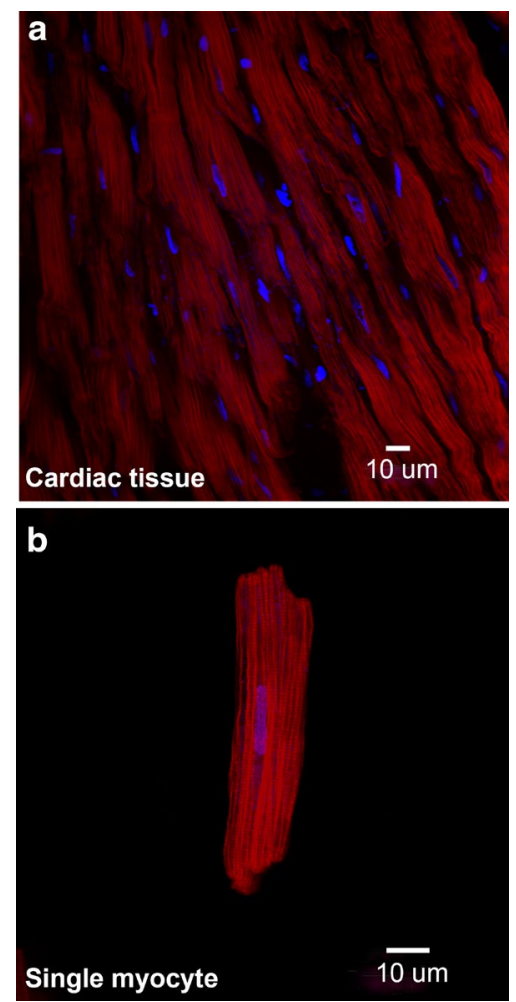

Fig. 2 Absence of ARL13B labelling in adult tissue and single myocytes. Representative confocal images dual immunolabelled for ARL13B (red) and nuclei (blue). a Adult rat cardiac tissue and b adult rat cardiomyocyte. A scale bar is shown for each image. ARL13B labelling was completely absent from both adult rat cardiac tissue and cardiomyocytes. A high background autofluorescence at lower intensity shows tissue and myocyte structure, with no ARL13B antibody labelling

\section{Immunolabelling in embryonic, neonatal, and young rat cardiac tissue}

Tissue sections from embryonic $(n=3)$, neonatal (P2, $n=2$ ), and young (P21 and P28, $n=3$ each) rat hearts were immunolabelled for primary cilia with anti-ARL13B antibody (Fig. 3a-d). Primary cilia were present in sections from embryonic, neonatal, and young cardiac tissue, which were located close to the nucleus of most cells. The distribution of primary cilia per nucleus appeared to be more abundant in embryonic sections in comparison to sections from neonatal and P2-P28 hearts.

\section{Primary cilia association to cell type in neonatal rat cardiac tissue}

Results showed primary cilia labelling was not associated with either endothelial cells (RECA-1 labelling, Fig. 4a) or fibroblasts (vimentin labelling, Fig. 4b, h and i) as shown in representative confocal images. Investigation of $3 \times 10 \mu \mathrm{m}$ tissue sections from P2, P21, and P28 rat hearts showed that primary cilia were not associated with fibroblasts (identified by vimentin labelling, and their smaller nuclei, Fig. 4g). Instead, the primary cilia were closely associated with myocyte contractile protein $\mathrm{f}$-actin labelling in tissue from all three postnatal stages, as shown in Fig. 4c-f.

\section{Discussion}

Previously, acetylated $\alpha$-tubulin-based approaches have been used as evidence of primary cilia from immunofluorescence. However, this antibody labels cytoplasmic microtubules, as well as defined microtubule structures, such as primary cilia [19, 22-24]. Acetylated $\alpha$-tubulin antibody also labels the tubulin associated with neurons, which are abundant in the heart [25]. We therefore utilized a more specific antibody for primary cilia which is a marker of the ARL13B protein, a small ciliary GTPase protein localized in the axonemal portion of the primary cilium and required for cilium biogenesis and maintenance [26, 27], and confirmed the presence of primary cilia in tissue from embryonic and developing rat hearts. Primary cilia are structures only $200-300 \mathrm{~nm}$ in diameter, and a few microns in length, making it technically difficult to capture them in a single plane in our images [28]. Hence, we include a video of Z-stacks from a positive control with primary cilia shown in different planes (Additional file 3: Figure S1(ii)). The specificity of anti-ARL13B antibody for primary cilia in the cardiovascular system has recently been reported in developing cardiomyocytes in culture [19], and in cultured endothelial cells [29]. 

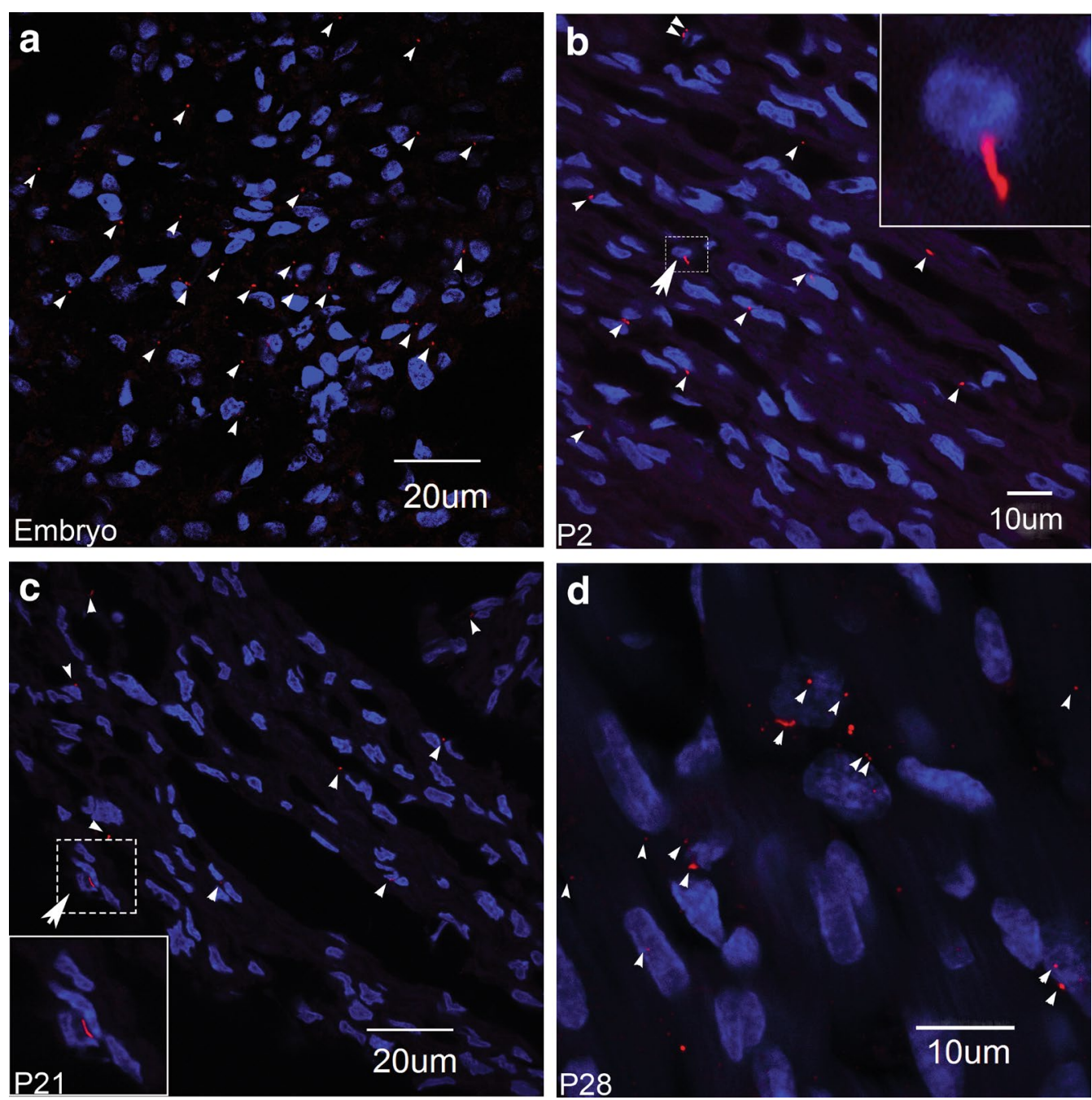

Fig. 3 ARL13B labelling of cardiac tissue from embryonic, neonatal, and young rat hearts. Confocal images immunolabelled for ARL13B (red) and nuclei (blue) in a embryonic, b neonatal (P2), and c, d young (P21 and P28) rat cardiac tissues. The small arrowheads show the presence of primary cilia in these images. Insets: magnified views of the primary cilia and nucleus from P2 and P21 rat cardiac tissue sections from the regions indicated by the large arrowheads

We found no evidence of ARL13B labelling in either cardiac tissue sections, or isolated myocytes, from adult rat hearts (Fig. 2). This was surprising, since primary cilia have previously been reported in adult human hearts, identified by electron microscopy [30]. In contrast, we observed ARL13B labelling of primary cilia in tissue sections from embryonic, neonatal (P2) and young (P21 and P28) rat hearts (Fig. 3a-d). The
ARL13B labelling was associated with the larger myocyte nuclei and f-actin myofilament protein (Fig. 4c-f).

\section{Conclusion}

We showed primary cilia are present in the early stages of rat heart development, but are missing from the myocardium of mature rat hearts. Primary cilia 

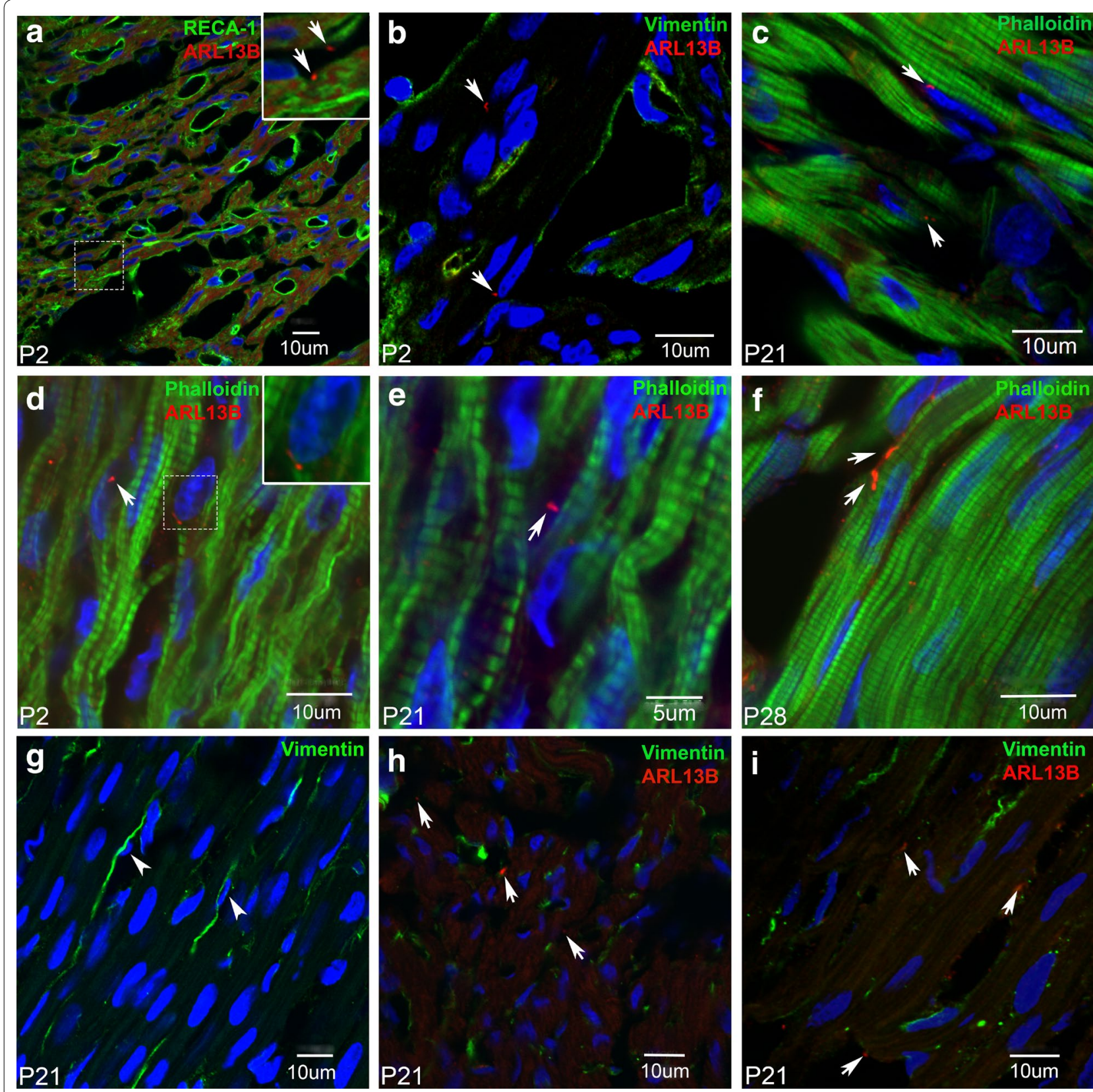

Fig. 4 Association of ARL13B with cell type in neonatal cardiac tissue. Representative confocal images of neonatal rat cardiac tissue sections triple immunolabelled with Hoechst (blue), ARL13B in red; with RECA-1 (a), vimentin (b), or phalloidin (c-f) labels in green. Cilia, identified by white arrows in each image, were not associated with either endothelial cells (a) or with interstitial fibroblasts (b, $\mathbf{h}, \mathbf{i}$, vimentin). ARL13B-positive structures always appeared to be associated with myocyte f-actin (c-f, phalloidin). White arrowheads ( $\mathbf{g}$ ) show fibroblasts with nuclei which are much smaller in size than the more abundant myocyte nuclei. Insets in $\mathbf{a}$ and $\mathbf{d}$ show magnified views of the dotted boxes 
cannot therefore explain the observed differences in $\mathrm{Ca}^{2+}$ homoeostasis between isolated myocytes and multicellular cardiac preparations from rat hearts.

\section{Additional files}

Additional file 1. Methods relating to the cardiac myocyte isolation procedure together with details of the solutions, reagents, and chemicals used.

\section{Additional file 2. Acetylated-a-tubulin labelling in adult cardiac} tissue. A series of Z-stacks showing intracellular and extracellular tubulin labelling by acetylated a-tubulin (red) in adult rat cardiac tissue. Regions of intense staining are shown in the extracellular space, along with some less prominent intracellular staining of microtubules, illustrating the inappropriateness of acetylated-a-tubulin for identification of primary cilia in the heart. The scale bar is $10 \mu \mathrm{m}$.

Additional file 3. Controls for acetylated a-tubulin and ARL13B antibodies. (i) Confocal images of rat kidney sections taken from glomerulus and tubule regions. A Negative, and $\mathbf{B}$ positive controls for acetylated-atubulin. C Negative, and D positive controls for ARL13B. The images show the presence of primary cilia in the glomerulus region of the kidney. Scale bars are shown for each image. (ii) A video of Z-stacks from the rat kidney glomerulus region stained with acetylated-a-tubulin as a positive control show primary cilia in different planes.

\section{Abbreviations}

$\left[\mathrm{Ca}^{2+}\right]_{0}$ : extracellular calcium; [Ca $\left.{ }^{2+}\right]_{i}$ : intracellular calcium; ARL13B: ADP ribosylation factor-like 13B; RECA-1: rat endothelial cell antigen-1; P2: postnatal day 2; P21: postnatal day 21; P28: postnatal day 28.

\section{Authors' contributions}

M-LW and SMCG conceived the experiments. SK performed the experiments, analysed the data, and prepared the manuscript. All the authors proofread, discussed the manuscript. All authors read and approved the final manuscript.

\section{Author details}

${ }^{1}$ Department of Physiology, School of Medical Sciences, Faculty of Medical and Health Sciences, The University of Auckland, Private Bag 92019, Auckland 1023, New Zealand. ${ }^{2}$ Department of Anatomy and Medical Imaging, School of Medical Sciences, Faculty of Medical and Health Sciences, The University of Auckland, Auckland, New Zealand.

\section{Competing interests}

The authors declare that they have no competing interests.

\section{Availability of data and materials}

The datasets used and/or analysed during the current study are available from the corresponding author on reasonable request.

\section{Consent for publication}

Not applicable.

\section{Ethics approval}

All experiments were conducted according to the guidelines of the Animal Ethics Committee at the University of Auckland, New Zealand, under the animal ethics \# (AEC 001232).

\section{Funding}

This research was funded by the Royal Society of New Zealand Marsden Fund [10-UOA-198 to M-LW]. SK was the recipient of a University of Auckland doctoral scholarship.

\section{Publisher's Note}

Springer Nature remains neutral with regard to jurisdictional claims in published maps and institutional affiliations.
Received: 21 February 2017 Accepted: 19 July 2018

Published online: 31 July 2018

\section{References}

1. Bers DM. Calcium cycling and signaling in cardiac myocytes. Annu Rev Physiol. 2008;70:23-49.

2. Kaur S, Kong CH, Cannell MB, Ward M-L. Depotentiation of intact rat cardiac muscle unmasks an Epac-dependent increase in myofilament $\mathrm{Ca}^{2+}$ sensitivity. Clin Exp Pharmacol Physiol. 2016;43:88-94.

3. Zimmerman K, Yoder BK. SnapShot: sensing and signaling by cilia. Cell. 2015:161(692-2):e1

4. Praetorius HA, Spring KR. A physiological view of the primary cilium. Annu Rev Physiol. 2005;67:515-29.

5. Wheatley DN, Wang AM, Strugnell GE. Expression of primary cilia in mammalian cells. Cell Biol Int. 1996;20:73-81.

6. Praetorius HA, Leipziger J. Released nucleotides amplify the ciliumdependent, flow-induced $\left[\mathrm{Ca}^{2+}\right]_{i}$ response in MDCK cells. Acta Physiol. 2009:197:241-51

7. Delling M, Indzhykulian AA, Liu X, Li Y, Xie T, Corey DP, et al. Primary cilia are not calcium-responsive mechanosensors. Nature. 2016:531:656-60.

8. Clement C, Ajbro K, Koefoed K, Vestergaard M, Veland I, HenriquesdeJesus $M$, et al. TGF- $\beta$ signaling is associated with endocytosis at the pocket region of the primary cilium. Cell Rep. 2013;3:1806-14.

9. Goetz SC, Anderson KV. The primary cilium: a signalling centre during vertebrate development. Nat Rev Genet. 2010;11:331-44.

10. Lienkamp S, Ganner A, Walz G. Inversin, Wnt signaling and primary cilia. Differentiation. 2012:83:S49-55.

11. Satir P, Pedersen LB, Christensen ST. The primary cilium at a glance. J Cell Sci. 2010;123(Pt 4):499-503.

12. Christensen ST, Clement CA, Satir P, Pedersen LB. Primary cilia and coordination of receptor tyrosine kinase (RTK) signalling. J Pathol. 2012;226:172-84

13. Goggolidou P, Wilson PD. Novel biomarkers in kidney disease: roles for cilia, Wnt signalling and ATMIN in polycystic kidney disease. Biochem Soc Trans. 2016:44:1745-51.

14. Koefoed K, Veland IR, Pedersen LB, Larsen LA, Christensen ST. Cilia and coordination of signaling networks during heart development. Organogenesis. 2014;10:108-25.

15. Badano JL, Mitsuma N, Beales PL, Katsanis N. The ciliopathies: an emerging class of human genetic disorders. Annu Rev Genomics Hum Genet. 2006;7:125-48

16. Edwards NC, Moody WE, Yuan M, Warfield AT, Cramb R, Paisey RB, et al. Diffuse left ventricular interstitial fibrosis is associated with sub-clinical myocardial dysfunction in Alström Syndrome: an observational study. Orphanet J Rare Dis. 2015;10:83.

17. Tasouri E, Tucker KL. Primary cilia and organogenesis: is Hedgehog the only sculptor? Cell Tissue Res. 2011;345:21-40.

18. Diguet N, Meilhac SM. Cilia and heart morphogenesis. Med Sci (Paris). 2014:30:996-1003.

19. Clement CA, Kristensen SG, Møllgård K, Pazour GJ, Yoder BK, Larsen LA, et al. The primary cilium coordinates early cardiogenesis and hedgehog signaling in cardiomyocyte differentiation. J Cell Sci. 2009;122(Pt 17):3070-82.

20. Higginbotham H, Eom TY, Mariani LE, Bachleda A, Hirt J, Gukassyan V, et al. Arl13b in primary cilia regulates the migration and placement of interneurons in the developing cerebral cortex. Dev Cell. 2012;23:925-38.

21. Deane JA, Verghese E, Martelotto LG, Cain JE, Galtseva A, Rosenblum ND, et al. Visualizing renal primary cilia. Nephrology. 2013;18:161-8.

22. Iomini C, Tejada K, Mo W, Vaananen H, Piperno G. Primary cilia of human endothelial cells disassemble under laminar shear stress. J Cell Biol. 2004;164:811-7.

23. Schatten G, Simerly C, Asai DJ, Szöke E, Cooke P, Schatten H. Acetylated alpha-tubulin in microtubules during mouse fertilization and early development. Dev Biol. 1988;130:74-86.

24. Piperno G, LeDizet M, Chang XJ. Microtubules containing acetylated alpha-tubulin in mammalian cells in culture. J Cell Biol. 1987:104:289-302.

25. Siddiqui SS, Aamodt E, Rastinejad F, Culotti J. Anti-tubulin monoclonal antibodies that bind to specific neurons in Caenorhabditis elegans. J Neurosci. 1989;9:2963-72. 
26. Caspary T, Larkins CE, Anderson KV. The graded response to Sonic Hedgehog depends on cilia architecture. Dev Cell. 2007;12:767-78.

27. Lu H, Toh MT, Narasimhan V, Thamilselvam SK, Choksi SP, Roy S. A function for the Joubert syndrome protein Arl13b in ciliary membrane extension and ciliary length regulation. Dev Biol. 2015;397:225-36.

28. Davis EE, Brueckner M, Katsanis N. The emerging complexity of the vertebrate cilium: new functional roles for an ancient organelle. Dev Cell. 2006;11:9-19.
29. Lim YC, McGlashan SR, Cooling MT, Long DS. Culture and detection of primary cilia in endothelial cell models. Cilia. 2015;4:11.

30. Myklebust R, Engedal H, Saetersdal TS, Ulstein M. Primary $9+0$ cilia in the embryonic and the adult human heart. Anat Embryol (Berl). 1977;151:127-39.
Ready to submit your research? Choose BMC and benefit from

- fast, convenient online submission

- thorough peer review by experienced researchers in your field

- rapid publication on acceptance

- support for research data, including large and complex data types

- gold Open Access which fosters wider collaboration and increased citations

- maximum visibility for your research: over $100 \mathrm{M}$ website views per year

At BMC, research is always in progress.

Learn more biomedcentral.com/submissions 